\title{
Effects of Intraduodenal Infusion of the Bitter Tastant, Quinine, on Antropyloroduodenal Motility, Plasma Cholecystokinin, and Energy Intake in Healthy Men
}

\author{
Vida Bitarafan, ${ }^{1}$ Penelope C E Fitzgerald, ${ }^{1}$ Tanya J Little, ${ }^{1}$ Wolfgang Meyerhof, ${ }^{2}$ Tongzhi Wu, ${ }^{1,3}$ Michael Horowitz, ${ }^{1,3}$ and \\ Christine Feinle-Bisset ${ }^{1 *}$ \\ ${ }^{1}$ Adelaide Medical School and National Health and Medical Research Council of Australia (NHMRC) Centre of Research Excellence in Translating \\ Nutritional Science to Good Health, University of Adelaide, Adelaide, Australia; ${ }^{2}$ Center for Integrative Physiology and Molecular Medicine, \\ Saarland University, Homburg, Germany; and ${ }^{3}$ Endocrine and Metabolic Unit, Royal Adelaide Hospital, Adelaide, Australia
}

\section{Background/Aims}

Nutrient-induced gut hormone release (eg, cholecystokinin [CCK]) and the modulation of gut motility (particularly pyloric stimulation) contribute to the regulation of acute energy intake. Non-caloric bitter compounds, including quinine, have recently been shown in cell-line and animal studies to stimulate the release of gastrointestinal hormones by activating bitter taste receptors expressed throughout the gastrointestinal tract, and thus, may potentially suppress energy intake without providing additional calories. This study aims to evaluate the effects of intraduodenally administered quinine on antropyloroduodenal pressures, plasma CCK and energy intake.

\section{Methods}

Fourteen healthy, lean men ( $25 \pm 5$ years; BMI: $\left.22.5 \pm 2.0 \mathrm{~kg} / \mathrm{m}^{2}\right)$ received on 4 separate occasions, in randomized, double-blind fashion, 60-minute intraduodenal infusions of quinine hydrochloride at doses totaling $37.5 \mathrm{mg}$ ("Q37.5"), $75 \mathrm{mg}$ ("Q75") or $225 \mathrm{mg}$ (“Q225”), or control (all $300 \mathrm{mOsmol}$ ). Antropyloroduodenal pressures (high-resolution manometry), plasma CCK (radioimmunoassay), and appetite perceptions/gastrointestinal symptoms (visual analog questionnaires) were measured. Ad libitum energy intake (buffet-meal) was quantified immediately post-infusion. Oral quinine taste-thresholds were assessed on a separate occasion using 3-alternative forced-choice procedure.

\section{Results}

All participants detected quinine orally (detection-threshold: $0.19 \pm 0.07 \mathrm{mmo} / \mathrm{L}$ ). Intraduodenal quinine did not affect antral, pyloric or duodenal pressures, plasma CCK (pmol/L [peak]; control: $3.6 \pm 0.4$, Q37.5: $3.6 \pm 0.4, Q 75: 3.7 \pm 0.3, Q 225: 3.9 \pm 0.4$ ), appetite perceptions, gastrointestinal symptoms or energy intake (kcal; control: $1088 \pm 90$, Q37.5: $1057 \pm 69$, Q75: $1029 \pm 7$ 0, Q225: $1077 \pm 88$ ).

\section{Conclusion}

Quinine, administered intraduodenally over 60 minutes, even at moderately high doses, but low infusion rates, does not modulate appetite-related gastrointestinal functions or energy intake.

(J Neurogastroenterol Motil 2019;25:413-422)

Key Words

Cholecystokinin; Energy intake; Gastrointestinal hormones; Pylorus; Quinine

Received: February 14, 2019 Revised: March 22, 2019 Accepted: April 7, 2019

(a) This is an Open Access article distributed under the terms of the Creative Commons Attribution Non-Commercial License (http://creativecommons. org/licenses/by-nc/4.0) which permits unrestricted non-commercial use, distribution, and reproduction in any medium, provided the original work is properly cited.

*Correspondence: Christine Feinle-Bisset, PhD

Adelaide Medical School, Faculty of Health and Medical Sciences, University of Adelaide, Adelaide SA 5005, Australia Tel: +61-8-8313-6053, Fax: +61-8-8313-7794, E-mail: christine.feinle@adelaide.edu.au 


\section{Introduction}

Dietary nutrients are known to potently modulate gastrointestinal (GI) functions, including gut hormones and motor functions that underlie the slowing of gastric emptying, resulting in reductions in energy intake and blood glucose. ${ }^{1-3}$ There is increasing interest in the effects of bitter compounds to stimulate these GI functions by activating subtypes of the taste 2 receptor (TAS2R) family of $\mathrm{G}$ protein-coupled receptors expressed on enteroendocrine cells throughout the human GI tract, ${ }^{4-7}$ particularly given the potential to suppress energy intake without providing additional calories.

The outcomes of studies in both cell lines and experimental animals suggest potent effects of bitter agonists to modulate gut hormone release. ${ }^{8-10}$ For example, denatonium benzoate (DB) and phenylthiocarbamide (PTC) have been reported to stimulate cholecystokinin (CCK) secretion from mouse STC-1 cells ${ }^{8}$ and DB to stimulate glucagon-like peptide-1 (GLP-1) and peptide YY (PYY) secretion from both human NCI-H716 cells and isolated duodenal tissue from mice. ${ }^{10}$ Moreover, intragastric DB and PTC, but not quinine hydrochloride $(\mathrm{Q}-\mathrm{HCl})$, stimulate the release of ghrelin in mice. ${ }^{9}$ Interestingly, in the latter study, PTC, but not DB or Q$\mathrm{HCl}$, slowed gastric emptying, which was unaffected by administration of either the CCK-A receptor antagonist, devazepide, or the GLP-1 antagonist, exendin-(9-39). ${ }^{9}$ Finally, in mice a mixture of bitter tastants, including Q-HCl, DB, and PTC, increased food intake in the first 30 minutes post-administration, while during the subsequent 4 hours there was a marked suppression of food intake. ${ }^{9}$ It is, however, important to note that some bitter agonists used in these studies (eg, $\mathrm{PTC}^{8}$ ), at the doses administered, have, in other studies, induced strong $\mathrm{Ca}^{2+}$ responses in control cells devoid of bitter receptors, ${ }^{11}$ thus, some of the reported effects may not be specific to bitter receptor activation.

In humans, studies relating to the effects of bitter agonists on gut hormone secretion, GI motility and/or energy intake have yielded inconsistent results and, if any, modest effects. ${ }^{5,6,12,13}$ Intragastric administration of $18 \mathrm{mg} \mathrm{Q}-\mathrm{HCl}$ in an acid-resistant capsule, had no effect on absolute plasma CCK concentrations, while the change in plasma CCK relative to baseline was slightly greater 30 minutes after consumption of a standardized meal following quinine compared with control, ${ }^{12}$ and intraduodenal infusion of a higher dose (75 mg) did not affect plasma CCK, GLP-1, or PYY. Intragastric administration of $10 \mu \mathrm{mol} / \mathrm{kg} \mathrm{Q}-\mathrm{HCl}(\sim 250 \mathrm{mg}$ in a $65 \mathrm{~kg}$ person) reduced plasma motilin and ghrelin moderately, while $\mathrm{DB},{ }^{6}$ or intraduodenal Q- $\mathrm{HCl}^{12}$ had no effect on ghrelin. Intragastric administration of DB impaired fundic relaxation ${ }^{4}$ and decreased antral, but not duodenal, motility, ${ }^{14}$ while Q- $\mathrm{HCl}$ reduced 'fluctuations in antral motility. ${ }^{6}$ Finally, intragastric Q-HCl (18 mg) modestly reduced energy intake ${ }^{12}$ and, at the much higher dose of $\sim 250 \mathrm{mg}$, the amount consumed of a palatable chocolate milk shake in healthy women, ${ }^{13}$ while intraduodenal Q- $\mathrm{HCl}$ at an intermediate dose (75 mg) had no effect. ${ }^{5}$

While these studies provide evidence that some bitter compounds modulate GI functions and energy intake, there are important issues which have not been addressed, including the effects of quinine across a wide range of doses, the relevance of the location of delivery (ie, stomach vs small intestine), and also whether any effects on energy intake are related to those on GI hormone and/or motor functions. The aim of this study was, therefore, to investigate the effects of intraduodenal infusion of a wide range of doses of quinine, given as Q-HCl, on upper GI motor function, gut hormones, appetite perceptions, and energy intake. We chose intraduodenal infusion because it allows delivery in a standardized fashion, without potential confounding influences from the rate of gastric emptying.

\section{Materials and Methods}

\section{Participants}

Fourteen healthy, lean, young men (mean age: $25 \pm 5$ years; body mass index [BMI]: $22.5 \pm 2.0 \mathrm{~kg} / \mathrm{m}^{2}$ ) participated in the study. Participants were recruited through flyers placed around the Royal Adelaide Hospital and local universities, and classified advertisements placed in local newspapers. Exclusion criteria were smoking, consumption of $>20 \mathrm{~g}$ alcohol/day, any medical condition, surgery, or the use of medications known to affect energy intake, appetite, or GI function. All participants were required to be weight-stable ( $<5 \%$ change in body weight) for at least 3 months before participation, and unrestrained eaters with a score of 12 on the eating-restraint component of the Three-Factor Eating Questionnaire. ${ }^{15}$ The Central Adelaide Local Health Network Human Research Ethics Committee approved the study protocol (Protocol No. HREC/16/RAH/410), and the study was performed in accordance with the Declaration of Helsinki. Each participant provided informed, written consent before their inclusion. Once a participant was enrolled into the study, they were assigned to a randomized treatment order generated by a research officer who was not involved in the data analysis, using an online tool. ${ }^{16}$ The study was registered as a clinical trial with the Australian New Zealand Clinical Trial Registry (Trial No. 12617000719336). ${ }^{17}$ 


\section{Study Outline}

The study evaluated the dose-related effects of 60-minute intraduodenal infusions of Q-HCl delivering either (1) $37.5 \mathrm{mg}$ (“Q37.5”, $0.625 \mathrm{mg} / \mathrm{min}$ ), (2) $75 \mathrm{mg}$ (“Q75”, $1.25 \mathrm{mg} / \mathrm{min}$ ) or (3) $225 \mathrm{mg}$ ("Q225”, $3.75 \mathrm{mg} / \mathrm{min}$ ), or (4) $0.9 \%$ saline ("control”), on antropyloroduodenal pressures, plasma CCK, appetite perceptions, GI symptoms and energy intake in healthy men (Fig. 1).

\section{Test Solutions}

Q-HCl solutions were prepared by dissolving $0.047 \mathrm{~g}, 0.094$ $\mathrm{g}$ or $0.281 \mathrm{~g}$ Q-HCl (Sinkona Indonesia Lestari, West Java, Indonesia) and $1.44 \mathrm{~g}, 1.44 \mathrm{~g}$, or $1.36 \mathrm{~g} \mathrm{NaCl}$, respectively, in $150 \mathrm{~mL}$ distilled water to achieve the required loads. The control solution contained $1.45 \mathrm{~g} \mathrm{NaCl}$ in $150 \mathrm{~mL}$ distilled water. All solutions were isotonic (300 mOsmol) and administered intraduodenally at a rate of $2 \mathrm{~mL} / \mathrm{min}$ for 60 minutes. The 2 lower doses of Q-HCl (37.5 $\mathrm{mg}$ and $75 \mathrm{mg}$ ) were selected based on studies in healthy subjects in which 18-75 $\mathrm{mg}$ Q-HCl reportedly stimulated CCK secretion, ${ }^{12}$

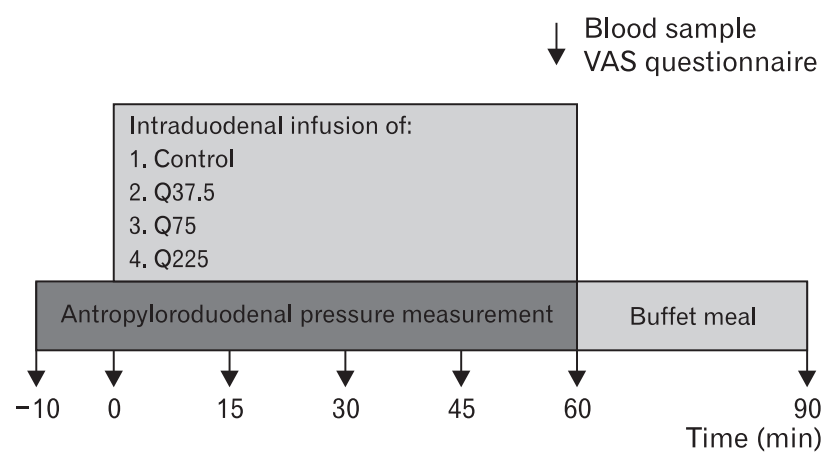

Figure 1. Schematic representation of the study design. At $t=-10$ minutes, immediately after the occurrence of a phase III, ie, during phase I, with the multi-lumen manometric catheter positioned across the pylorus, a baseline blood sample was collected, and the participant completed a visual analogue scale (VAS) questionnaire for the assessment of appetite-related perceptions. The recording of pressures in the antropyloroduodenal region was also commenced. At $\mathrm{t}=0$ minutes, intraduodenal infusion of quinine hydrochloride at $37.5 \mathrm{mg}$ (Q37.5), $75 \mathrm{mg}$ (Q75), $225 \mathrm{mg}$ (Q225), or control commenced for 60 minutes. During the infusion, antropyloroduodenal pressures were recorded continuously, and blood samples and VAS ratings were collected at 15 -minute intervals. At $\mathrm{t}=60$ minutes, the intraduodenal infusion was terminated, and the catheter removed. The participant was then presented with a buffet-style meal and instructed to eat until he was comfortably full. At $t=90$ minutes, another blood sample was collected, and a VAS questionnaire administered, after which the participant was free to leave the laboratory. and reduced, ${ }^{12}$ or had no effect on energy intake. ${ }^{5}$ The dose of 225 $\mathrm{mg}$ was chosen based on recent reports that Q- $\mathrm{HCl}$ at $\sim 250 \mathrm{mg}$ reduced the release of both motilin and ghrelin as well as hedonic eating moderately. 6

\section{Study Protocol}

Each participant was studied on 4 occasions, separated by 3-10 days, in a randomized, double-blind fashion. Participants were instructed to refrain from vigorous exercise and alcohol consumption for 24 hours before each study and were provided with a standardized meal (Beef Lasagne; McCain Food, Wendouree, Victoria, Australia; energy content: $602 \mathrm{kcal}$ ) to be consumed by 7:00 PM on the night before each visit.

On each study day, the participant arrived at the Clinical Research Facility at the Adelaide Medical School, University of Adelaide, at 8:00 AM after an overnight fast (from food and fluids except water after 7:00 PM, and from water after 6:30 AM). On arrival, an intravenous cannula was placed in a right forearm vein for blood sampling, and the participant was intubated with a smalldiameter (external diameter: $3.5 \mathrm{~mm}$ ), 17-channel manometric catheter (Dentsleeve International, Mui Scientific, Mississauga, Ontario, Canada), which was inserted into the stomach through an anaesthetized nostril and allowed to pass into the duodenum by peristalsis. ${ }^{18}$ The manometric catheter consisted of 16 side-holes spaced at $1.5 \mathrm{~cm}$ intervals, measuring pressures in the antrum, pylorus, and duodenum. ${ }^{19,20}$ An additional channel was positioned $\sim 14.5 \mathrm{~cm}$ distal to the pylorus and used for intraduodenal infusion of $\mathrm{Q}-\mathrm{HCl}$ or control solutions. The correct positioning of the catheter was maintained by continuous measurement of the transmucosal potential difference between the most distal antral, and the most proximal duodenal, channels. ${ }^{21}$ Once the catheter was positioned correctly (within $59 \pm 4$ minutes across study days and participants) and immediately after the occurrence of a phase III of the interdigestive migrating motor complex (time from catheter insertion to the occurrence of phase III (minutes); control: $67 \pm$ 7, Q37.5: $72 \pm 11$, Q75: $84 \pm 16$, Q225: $76 \pm 14$, NS), during phase I (a period of motor quiescence), a baseline blood sample was collected, and the participant completed a visual analogue scale (VAS) questionnaire to assess appetite-related perceptions (hunger, fullness, desire to eat, prospective food consumption), and GI symptoms (nausea, bloating), ${ }^{22}$ and fasting motility was monitored continuously for 10 minutes $(t=-10-0$ minutes). At $t=0$ minutes, intraduodenal infusion of either $\mathrm{Q}-\mathrm{HCl}$ or control commenced for 60 minutes. During the infusion, antropyloroduodenal pressures were recorded continuously, while blood samples for 
measurement of gut hormones and blood glucose were collected, and VAS questionnaires completed every 15 minutes. At $\mathrm{t}=60$ minutes, the intraduodenal infusion was terminated and the participant extubated. The participant was then presented with a standardized, cold, buffet-style meal and instructed to consume as much, or as little, food as they wished until they felt comfortably full, for up to 30 minutes ( $t=60-90$ minutes). ${ }^{23}$ The meal comprised 4 slices $(\sim 120 \mathrm{~g})$ of whole-meal bread, 4 slices $(\sim 120 \mathrm{~g})$ of white bread, $100 \mathrm{~g}$ sliced ham, $100 \mathrm{~g}$ sliced chicken, $85 \mathrm{~g}$ sliced cheddar cheese, $100 \mathrm{~g}$ lettuce, $100 \mathrm{~g}$ sliced tomato, $100 \mathrm{~g}$ sliced cucumber, $22 \mathrm{~g}$ mayonnaise, 20 g margarine, 1 apple ( $\sim 170 \mathrm{~g}), 1$ banana $(\sim 190 \mathrm{~g})$, $175 \mathrm{~g}$ strawberry yogurt, $100 \mathrm{~g}$ chocolate custard, $120 \mathrm{~g}$ fruit salad, $375 \mathrm{~mL}$ iced coffee, $300 \mathrm{~mL}$ orange juice, and $600 \mathrm{~mL}$ water. The buffet meal had a total energy content of $\sim 2300 \mathrm{kcal}$ ( $\sim 27 \%$ fat, $\sim 52 \%$ carbohydrate, and $\sim 21 \%$ protein) and weight of $\sim 2924 .^{23}$ At $\mathrm{t}=90$ minutes, after completion of the meal, a final blood sample was taken, and the VAS completed, and the participant was then allowed to leave the laboratory.

On a separate day, oral taste detection thresholds for Q- $\mathrm{HCl}$ were quantified. $^{24}$

\section{Measurements}

\section{Oral quinine taste-thresholds}

Detection thresholds for $\mathrm{Q}-\mathrm{HCl}$ were determined using the ascending series 3-Alternate Forced Choice technique. ${ }^{24}$ Participants were asked to abstain from food, beverages and oral care products for at least 2 hours prior to the test, and to prevent confounding from non-taste sensory inputs, all tests were conducted while wearing nose clips. Taste samples were prepared by adding $\mathrm{Q}-\mathrm{HCl}$ at varying concentrations $(0.00125,0.0025,0.0125,0.025,0.075$, $0.25,0.75,1.5,3,7.5,15,30$, and $75 \mathrm{mmol} / \mathrm{L})$ to distilled water. ${ }^{25}$ Control samples consisted of distilled water. Samples were prepared fresh on the day of testing. Participants were presented with 3 samples per set, 2 controls and 1 containing $\mathrm{Q}-\mathrm{HCl}$, in ascending order from the lowest to the highest concentration. Participants rinsed their mouth with distilled water before beginning the task and between each sample set. In each set, participants were asked to identify the "odd" sample. If incorrect, they were presented with 3 samples at the next higher concentration and, if correct, with 3 more samples at the same concentration. This procedure continued until the participant identified the odd sample at a given concentration 3 consecutive times, and that concentration was defined as their detection threshold for Q- $\mathrm{HCl}$.

\section{Appetite perceptions, gastrointestinal symptoms, and energy intake}

Appetite perceptions (including hunger, fullness, desire to eat, and prospective food consumption) were quantified with validated 100-mm VAS questionnaires. ${ }^{22}$ Nausea and bloating were also assessed. Energy intake (kcal) was calculated from the amount of food and liquids (g) consumed at the buffet meal, measured by weighing each food item before presentation and at the end of the meal, using commercial software (FoodWorks 8.0; Xyris Software, Highgate Hill, Queensland, Australia). ${ }^{23}$

\section{Antropyloroduodenal motility}

Antropyloroduodenal pressures were digitized and recorded using a computer-based system running commercially available software (Solar GI, MMS Data base software, version 8.17; Medical Measurement Systems BV, Enschede, The Netherlands), and stored for subsequent analysis. The number and amplitude of antral, isolated pyloric, and duodenal pressure waves, as well as basal pyloric pressure, using custom-written software modified to our requirements (kindly provided by Professor Emeritus A Smout, University Medical Centre, Amsterdam, The Netherlands), as described previously. ${ }^{26}$

\section{Plasma cholecystokinin and blood glucose concentrations}

Blood samples were collected into ice-chilled ethylenediaminetetraacetic acid-coated tubes. Plasma was separated by centrifuga-

Table 1. Energy Content and Amount of Food and Liquids Consumed at the Buffet Meal Immediately After 60-minute Intraduodenal Infusions of Quinine Hydrochloride or Control

\begin{tabular}{ccccc}
\hline Parameter & C & Q37.5 & Q75 & Q225 \\
\hline Energy intake $(\mathrm{kcal})$ & $1088 \pm 90$ & $1057 \pm 69$ & $1029 \pm 70$ & $1077 \pm 88$ \\
Amount consumed $(\mathrm{g})$ & $1157 \pm 90$ & $1161 \pm 84$ & $1113 \pm 76 \quad 1144 \pm 98$ \\
\hline
\end{tabular}

C, saline control; Q37.5, quinine hydrochloride load of $37.5 \mathrm{mg}$; Q75, quinine hydrochloride load of 75 mg; Q225, quinine hydrochloride load of 225 mg; NS, nonsignificant.

Data are means \pm SEMs $(\mathrm{n}=14)$.

$P$-values for main treatment effects were determined by one-way ANOVA. 
A

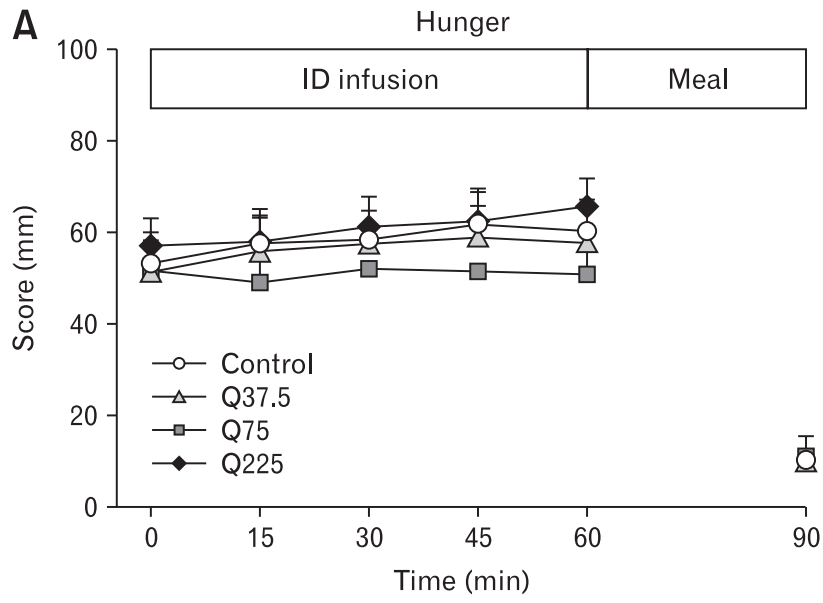

C

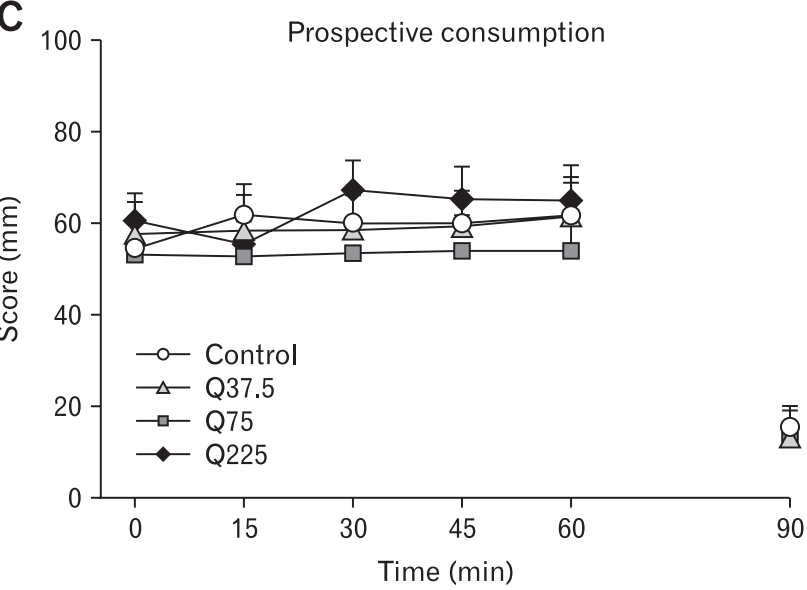

E

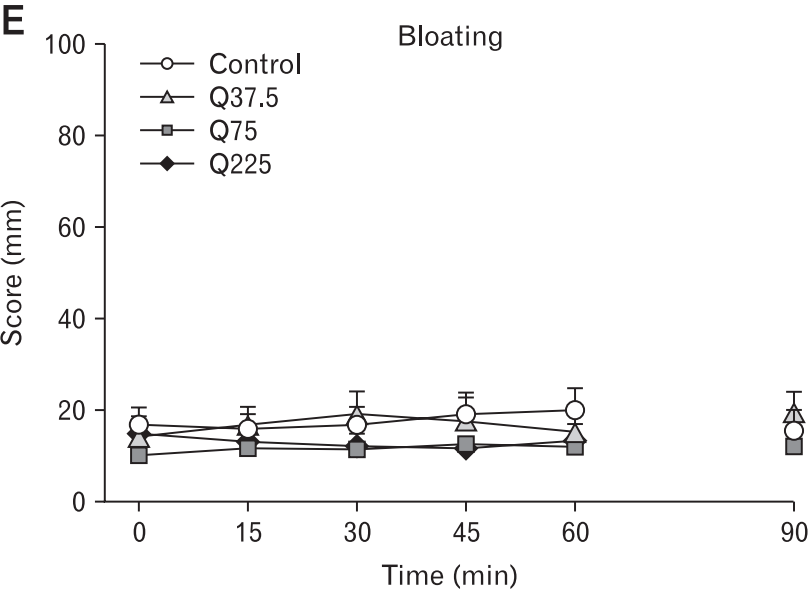

B
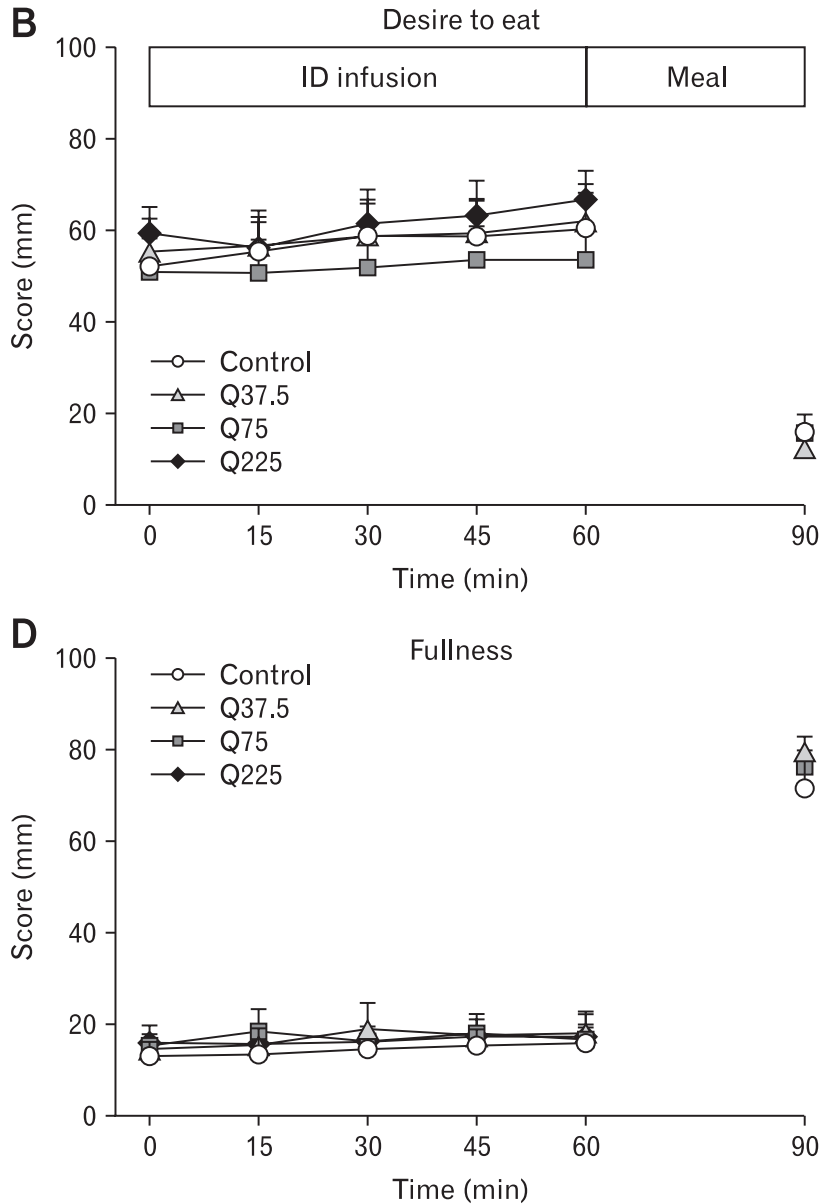

F

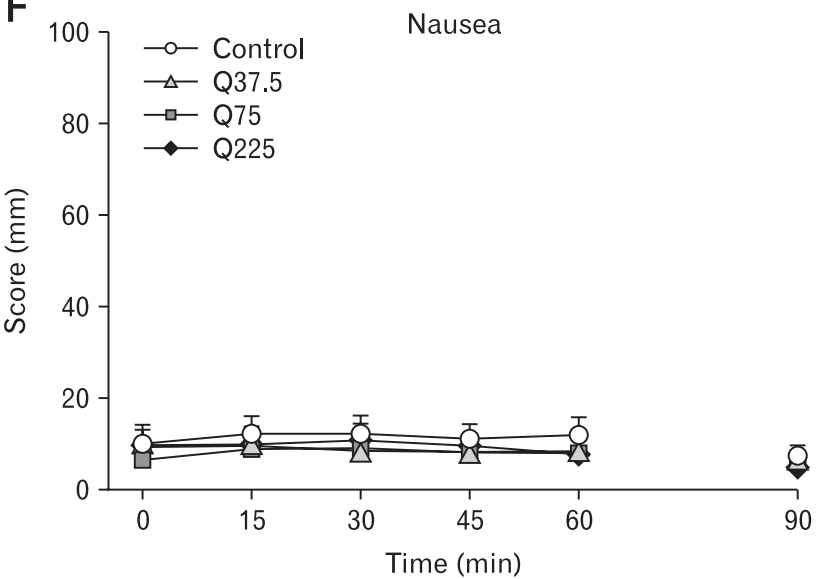

Figure 2. Scores for hunger (A), desire to eat (B), prospective food consumption (C), fullness (D), bloating (E), and nausea (F) during 60-minute intraduodenal infusions ( $\mathrm{t}=$ 0-60 minutes) of quinine hydrochloride at $37.5 \mathrm{mg}$ (Q37.5), $75 \mathrm{mg}(\mathrm{Q} 75), 225 \mathrm{mg}$ (Q225), or control, and after the buffet meal, at $\mathrm{t}=90$ minutes. Two-way ANOVAs, with treatment and time as factors, were used to assess differences between treatments. Posthoc comparisons, adjusted for multiple comparisons by Bonferroni's correction, were used to determine significant differences between either dose or control. Comparisons of post $(\mathrm{t}=90$ minutes $)$ vs pre-meal $(\mathrm{t}=60$ minutes $)$ data were done with Student's paired $t$ test. Data are expressed as means \pm SEMs; $n=14$. ID, intraduodenal. 
tion at $\sim 1830 \mathrm{~g}$ for 15 minutes at $4^{\circ} \mathrm{C}$ within 15 minutes of collection and stored at $-70^{\circ} \mathrm{C}$ until assayed.

Plasma CCK-8 concentrations ( $\mathrm{pmol} / \mathrm{L}$ ) were measured by radioimmunoassay after ethanol extraction using an adaptation of the method of Santangelo et al. ${ }^{27}$ Intra- and inter-assay coefficients of variation were $\sim 9.2 \%$ and $13.7 \%$, respectively. The detection limit was $1 \mathrm{pmol} / \mathrm{L}$.

Blood glucose was determined with a portable glucometer (Medisense Precision QLD; Abbott Laboratories, North Ryde, New South Wales, Australia), and was quantified because of the potential of quinine to cause hypoglycaemia.

\section{Statistical Methods}

The number of participants was determined by power calculations based on our previous work. ${ }^{28}$ We calculated that with 14 participants, we would be able to detect a $15 \%$ decrease in energy intake at $\alpha=0.05$, with a power of $80 \%$.

Baseline values for all data were calculated as means of values obtained between $\mathrm{t}=-10$ and $\mathrm{t}=0$ minutes. For antral, isolated pyloric, and duodenal pressure waves, total numbers, and mean amplitudes were calculated over the 60-minute infusion period. Number and amplitude of antral and duodenal pressure waves were used to calculate motility indices (MI) using the following equation: $\mathrm{MI}$ (mmHg.number) $=$ natural logarithm $\{$ [sum of amplitudes $\times$ number of contractions (pressure waves) $]+1\} .^{29}$ Basal pyloric pressures were averaged over the 60-minute infusion period. Plasma CCK and blood glucose concentrations were measured in duplicate and expressed as means at each time point.

Statistical analyses were performed with SPSS software (version 24.0; IBM Corp, Somers, NY, USA). VAS scores, plasma CCK and blood glucose concentrations were analyzed using repeatedmeasures 2-way ANOVA, with treatment (Q37.5, Q75, Q225, and control) and time (0-60 minutes) as factors. Sphericity of the time effect for all models was evaluated by Mauchly's test and, when violated, the adjusted Greenhouse-Geisser $P$-value was reported. Motility data, energy intake and amount of food and liquids consumed from the test meal were analyzed using one-way ANOVA. Post-hoc comparisons, adjusted for multiple comparisons by Bonferroni's correction, were performed where ANOVAs revealed significant effects. Comparisons of post-meal $(t=90$ minutes $)$ vs pre-meal $(t$ $=60$ minutes) $\mathrm{CCK}$ and glucose concentrations were done using Student's paired $t$ test. All data are reported as means \pm SEMs. All tests were 2-tailed, and differences were considered statistically significant at $P<0.05$.

\section{Results}

All subjects completed all 4 study visits and tolerated the experimental procedures well, and detected Q- $\mathrm{HCl}$ orally (detectionthreshold: $0.19 \pm 0.07 \mathrm{mmol} / \mathrm{L}$ ).

\section{Energy Intake}

There was no effect of treatment on energy intake (kcal) or the amount consumed (g) from the buffet meal (Table 1).

Table 2. Number, Amplitude, and Motility Index of Antral and Duodenal Pressure Waves, Basal Pyloric Pressure, and Number and Amplitude of Isolated Pyloric Pressure Waves During 60-minute Intraduodenal Infusions of Quinine Hydrochloride or Control

\begin{tabular}{|c|c|c|c|c|c|}
\hline Parameter & $\mathrm{C}$ & Q37.5 & Q75 & Q225 & $P$-value \\
\hline \multicolumn{6}{|l|}{ Antral pressure waves } \\
\hline Number & $39 \pm 13$ & $27 \pm 11$ & $37 \pm 12$ & $29 \pm 13$ & NS \\
\hline Amplitude (mmHg) & $29 \pm 6$ & $21 \pm 7$ & $30 \pm 5$ & $43 \pm 11$ & NS \\
\hline Motility index $(\mathrm{mmHg} \cdot \mathrm{min})$ & $8 \pm 1$ & $6 \pm 1$ & $9 \pm 1$ & $7 \pm 1$ & NS \\
\hline Basal pyloric pressure (mmHg) & $1 \pm 1$ & $-2 \pm 1$ & $0 \pm 0$ & $-1 \pm 1$ & NS \\
\hline \multicolumn{6}{|l|}{ Isolated pyloric pressure waves } \\
\hline Number & $21 \pm 5$ & $15 \pm 3$ & $22 \pm 6$ & $16 \pm 4$ & NS \\
\hline Amplitude (mmHg) & $76 \pm 9$ & $73 \pm 16$ & $59 \pm 8$ & $51 \pm 10$ & NS \\
\hline \multicolumn{6}{|l|}{ Duodenal pressure waves } \\
\hline Number & $253 \pm 31$ & $266 \pm 52$ & $248 \pm 32$ & $235 \pm 46$ & NS \\
\hline Amplitude (mmHg) & $26 \pm 1$ & $28 \pm 2$ & $24 \pm 2$ & $25 \pm 1$ & NS \\
\hline Motility index $(\mathrm{mmHg} \cdot \mathrm{min})$ & $14 \pm 0$ & $14 \pm 0$ & $14 \pm 0$ & $14 \pm 0$ & NS \\
\hline
\end{tabular}

C, saline control; Q37.5, quinine hydrochloride load of $37.5 \mathrm{mg}$; Q75, quinine hydrochloride load of 75 mg; Q225, quinine hydrochloride load of 225 mg; NS, nonsignificant.

Data are means \pm SEMs $(\mathrm{n}=14)$.

$P$-values for main treatment effects were determined by one-way ANOVA. 

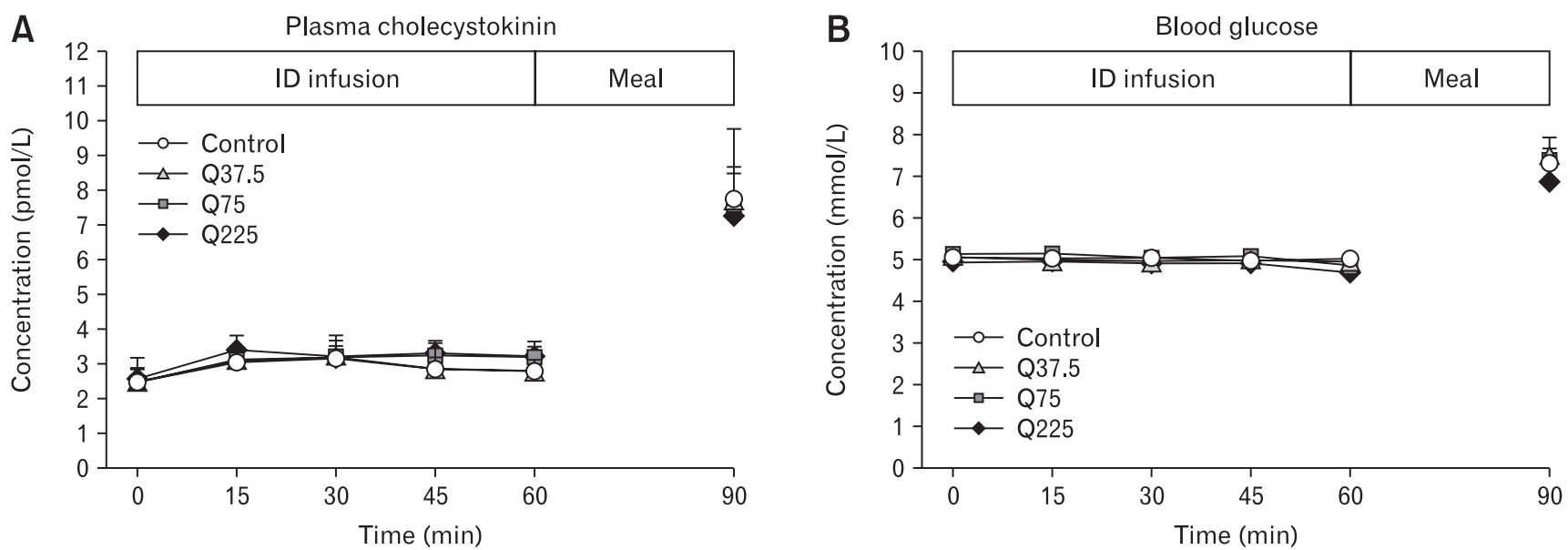

Figure 3. Plasma cholecystokinin (A) and blood glucose (B) concentrations during 60-minute intraduodenal infusions ( $\mathrm{t}=0$-60 minutes) of quinine hydrochloride at $37.5 \mathrm{mg}(\mathrm{Q} 37.5), 75 \mathrm{mg}(\mathrm{Q} 75), 225 \mathrm{mg}(\mathrm{Q} 225)$, or control, and after the buffet meal, at $\mathrm{t}=90$ minutes. Data were analyzed using 2-way ANOVA, with treatment and time as factors. Comparison of post ( $\mathrm{t}=90$ minutes) vs pre-meal $(\mathrm{t}=60$ minutes $)$ concentrations were done with Student's paired $t$ test. Data are expressed as means \pm SEMs; $n=14$. ID, intraduodenal.

\section{Appetite Perceptions and Gastrointestinal Symptoms}

There were no differences in baseline ratings, or any effect of treatment or time, on ratings of hunger, desire to eat, prospective food consumption, fullness, nausea, or bloating (Fig. 2A-F).

\section{Antropyloroduodenal Pressures}

Baseline values for antral, pyloric or duodenal pressures did not differ between study days, and there was no effect of treatment on the total number, mean amplitude, or MI, of antral or duodenal pressures, basal pyloric pressure or the number or amplitude of isolated pyloric pressure waves (Table 2).

\section{Plasma Cholecystokinin Concentrations}

There were no differences in baseline plasma CCK concentrations between study days, and no effect of treatment on plasma CCK. Plasma CCK increased substantially in response to the buffet meal with all treatments (time effect: $P<0.05$ ), with no difference between treatments (Fig. 3A).

\section{Blood Glucose Concentrations}

There were no differences in baseline values for blood glucose between study days, and no effect of treatment on blood glucose. In response to the buffet meal, blood glucose increased with all treatments (time effect: $P<0.05$ ), with no difference between treatments (Fig. 3B).

\section{Discussion}

Our study indicates that slow intraduodenal administration of quinine over 60 minutes, at the loads used, does not affect the acute antropyloroduodenal motility, plasma CCK or energy intake responses to quinine, and, therefore, at least under these conditions, does not appear to be a potent stimulus for small-intestinal bitter taste receptors to modulate appetite-related GI functions and energy intake.

There has been much interest in characterising the effects of bitter compounds on gut hormone release, ${ }^{8-10,12}$ since (1) bitter taste receptors are expressed on enteroendocrine cells in the GI lumen, (2) gut hormones, including CCK, GLP-1, and PYY, mediate the effects of nutrients on GI motor function and gastric emptying, and (3) gut hormones play a critical role in the regulation of appetite and energy intake. ${ }^{3,30}$ Results from studies in humans have, however, been inconsistent, and effects, if any, appear to be modest. ${ }^{5,6,12-14} \mathrm{We}$ were particularly interested in the effect of quinine on CCK, given the findings in preclinical studies of potent CCK release by other bitter substances ${ }^{8}$ and our previous work in humans demonstrating potent release of CCK by dietary nutrients, associated with marked suppression of energy intake. ${ }^{19,28}$ In line with the previous studies in humans on the effects of quinine on plasma CCK levels, ${ }^{5,12}$ we found no effect of even the highest dose of intraduodenal quinine on plasma CCK concentrations. Thus, our data suggest that $\mathrm{Q}-\mathrm{HCl}$, administered at a slow rate, is not a potent stimulus for enteroendocrine cells that release $\mathrm{CCK}$.

Previous studies on the effects of bitter compounds on GI mo- 
tor functions have yielded diverse, and inconsistent, outcomes. For example, in mouse gastric tissue, DB and chloroquine stimulated, while PTC inhibited, antral contractility. ${ }^{4}$ Moreover, in mice, intragastric gavage of $\mathrm{PTC}$, but not $\mathrm{DB}$ or $\mathrm{Q}-\mathrm{HCl}$, slowed gastric emptying. ${ }^{9}$ In humans, intragastric administration of $\mathrm{DB}$ has been reported to impair nutrient-induced fundic relaxation ${ }^{4}$ and decrease antral, but not duodenal, motility, but to have no effect on gastric emptying of a solid meal. ${ }^{14}$ Intragastric administration of $250 \mathrm{mg}$ reduced 'fluctuations in antral motility. ${ }^{6}$ We found that intraduodenal infusion of $\mathrm{Q}-\mathrm{HCl}$, using a wide range of doses that spanned those used in previous studies of the effects of quinine on gut hormone release, motility, and energy intake, ${ }^{5,6,12}$ had no effect on antral, pyloric or duodenal pressures, suggesting that quinine, when administered intraduodenally at a slow rate, at the loads used, does not modulate antropyloroduodenal motility in humans. Since CCK potently modulates upper GI motor function, ${ }^{31-33}$ the absence of CCK release in the current study likely explains the lack of effect of Q-HCl on antropyloroduodenal pressures.

In line with the lack of effect of Q-HCl to modulate upper GI motility, particularly pyloric pressures, or stimulate CCK, both of which we have identified as key determinants of the subsequent suppression of energy intake in response to duodenal nutrients, ${ }^{1,34}$ we found no effect of $\mathrm{Q}-\mathrm{HCl}$ to reduce appetite or energy intake. In a recent study, DB reduced hunger ratings in the fasting state, and decreased hunger and increased satiety after a meal, but did not significantly reduce caloric intake from a standardized meal, with substantial variability between individuals. ${ }^{14}$ Moreover, while intragastric administration of $18 \mathrm{mg}$ Q- $\mathrm{HCl}$ reduced energy intake in one study ${ }^{12}$ and, at a much higher dose $(\sim 250 \mathrm{mg})$, modestly reduced the amount consumed of a palatable milk shake in healthy females, ${ }^{13}$ intraduodenal infusion of $75 \mathrm{mg}$ Q- $\mathrm{HCl}$ was ineffective. ${ }^{5}$ Thus, overall findings are mixed, and more studies are warranted to determine the conditions under which bitter substances, including $\mathrm{Q}-\mathrm{HCl}$, stimulate $\mathrm{GI}$ functions that underlie the regulation of energy intake, and suppress energy intake.

A key issue with the existing research on the effects of bitter compounds on GI function and energy intake is the substantial variation in outcomes between studies, which is potentially attributable to a number of factors. These include variations in the bitter compounds used and the doses applied, administration of the compounds to cell models vs into the stomach or small intestine of humans or animals, and using either bolus administration or slower infusions over time.-6,8,10,12-14 There are currently 25 known subtypes of TAS2Rs in humans, ${ }^{35}$ and different bitter agonists activate different combinations of receptor subtypes, for example, quinine activates 9 subtypes of TAS2Rs, including TAS2R4, 7, 10, $14,39,40,43,44$, and 46 , and DB activates 8 subtypes, including TAS2R4, 8, 10, 13, 39, 43, 46, and 47 . $^{35}$ The difference in the subtypes of TAS2Rs that are activated by each bitter compound, ${ }^{35}$ as well as species differences in TAS2Rs, ${ }^{11}$ are likely to explain some of the differences in observed effects. Stimulation of the release of gut hormones by bitter compounds depends on the presence of specific bitter receptor subtypes on enteroendocrine cells; evidence of the identity, and functions, of some subtypes on enteroendocrine cells is emerging. For example, a recent study in humans reported that TAS2R38s are expressed on human colonic enteroendocrine cells and are colocalized with immunoreactivity for CCK, GLP-1 or PYY. $^{36}$ Interestingly, neither quinine nor DB activate the TAS2R38 subtype. $^{35}$ The regional distribution of bitter receptor subtypes across the stomach, small and large intestines may also vary. ${ }^{37}$ Thus, much more research is required to better understand the roles and functions of the various bitter receptor subtypes in humans, as well as their specific activation by particular bitter compounds. Interindividual variations in bitter taste perception that have been documented for oral taste ${ }^{38}$ may also exist in the gut and, thus, influence the responses to intraluminal bitter compounds. Finally, the GI responses to bitter substances may be influenced by the habitual diet, in analogy to fat, ${ }^{39}$ with evidence of an inverse relationship between intake of bitter vegetables and the ability to taste the bitter substance, 6-n-propylthiouracil in children; ${ }^{40}$ furthermore, the ability to taste bitter may also be modified by dietary energy and fat consumption. $^{41,42}$

Some potential limitations of our study should be recognized. We only studied males, as they have been shown to be more sensitive to dietary manipulations, ${ }^{43}$ while, in contrast, it has been reported recently ${ }^{14}$ that females appear to be more sensitive to bitter taste, however, all our volunteers readily detected Q-HCl. Our study evaluated the effects of intraduodenal, rather than intragastric or oral, Q-HCl administration, thus, studies are warranted to elucidate the relative contributions of gastric and oral perception of bitter taste to the regulation of GI functions and appetite. We only analyzed the effects on plasma CCK concentrations, and not other gut hormones, including GLP-1, PYY, or ghrelin, but given that we found no effects on GI motility or energy intake, we believe that any effects on other hormones would be unlikely.

In conclusion, our study establishes that intraduodenal administration of Q- $\mathrm{HCl}$, over a wide range of doses, when infused over a 60-minute period, does not affect antropyloroduodenal pressures, plasma CCK or energy intake. Further studies are warranted that evaluate conditions under which quinine may stimulate bitter recep- 
tors to modulate appetite-related GI functions and energy intake, including the effects of varying concentrations of quinine, and the relative effects of oral, intragastric and intraduodenal administration.

Acknowledgements: We thank Kylie Lange, National Health and Medical Research Council of Australia (NHMRC) Centre of Research Excellence in Translating Nutritional Science to Good Health, The University of Adelaide, a professional biostatistician, for statistical support, and Mr Scott Standfield for performing the biochemical assay for cholecystokinin.

Financial support: The authors acknowledge the following sources of funding: International Postgraduate Scholarship provided by the University of Adelaide (2017-20; to Vida Bitarafan), NHMRC Senior Research Fellowship (Grant No. 1103020 , 2016-21; to Christine Feinle-Bisset), NHMRC Career Development Award (Grant No. 1022706, 2012-19; to Tanya J Little), Florey Fellowship from the Royal Adelaide Hospital Research Foundation (ID: 9757, 2018-20; to Tongzhi Wu), and NHMRC Project Grant, which funded this research (Grant No. 1078471, 2015-19; to Christine Feinle-Bisset).

Conflicts of interest: The authors declare no conflict of interest. The sponsors had no role in the design of the study, the collection, analyses, or interpretation of data, writing of the manuscript, and in the decision to publish the results.

Author contributions: Christine Feinle-Bisset and Tanya J Little contributed to study concept and design; Vida Bitarafan and Penelope C E Fitzgerald conducted experiments; Vida Bitarafan analyzed data; Vida Bitarafan, Tanya J Little, Wolfgang Meyerhof, Tongzhi Wu, Michael Horowitz, and Christine Feinle-Bisset interpreted results of experiments; Vida Bitarafan and Christine Feinle-Bisset drafted manuscript; Vida Bitarafan, Penelope C E Fitzgerald, Tanya J Little, Wolfgang Meyerhof, Tongzhi Wu, Michael Horowitz, and Christine Feinle-Bisset edited and revised manuscript; Vida Bitarafan, Penelope C E Fitzgerald, Tanya J Little Wolfgang Meyerhof, Tongzhi Wu, Michael Horowitz, and Christine Feinle-Bisset approved final version of manuscript; and Christine Feinle-Bisset acquired funding and had overall responsibility for the project.

\section{References}

1. Seimon RV, Lange K, Little TJ, et al. Pooled-data analysis identifies pyloric pressures and plasma cholecystokinin concentrations as major determinants of acute energy intake in healthy, lean men. Am J Clin Nutr 2010;92:61-68.

2. Ma J, Stevens JE, Cukier K, et al. Effects of a protein preload on gastric emptying, glycemia, and gut hormones after a carbohydrate meal in dietcontrolled type 2 diabetes. Diabetes Care 2009;32:1600-1602.

3. Steinert RE, Feinle-Bisset C, Asarian L, Horowitz M, Beglinger C, Geary N. Ghrelin, CCK, GLP-1, and PYY(3-36): secretory controls and physiological roles in eating and glycemia in health, obesity, and after RYGB. Physiol Rev 2017;97:411-463.

4. Avau B, Rotondo A, Thijs T, et al. Targeting extra-oral bitter taste receptors modulates gastrointestinal motility with effects on satiation. Sci Rep 2015;5:15985

5. van Avesaat M, Troost FJ, Ripken D, Peters J, Hendriks HF, Masclee AA. Intraduodenal infusion of a combination of tastants decreases food intake in humans. Am J Clin Nutr 2015;102:729-735.

6. Deloose E, Corsetti M, Van Oudenhove L, Depoortere I, Tack J. Intragastric infusion of the bitter tastant quinine suppresses hormone release and antral motility during the fasting state in healthy female volunteers. Neurogastroenterol Motil 2018;30:e13171.

7. Xie C, Wang X, Young RL, Horowitz M, Rayner CK, Wu T. Role of intestinal bitter sensing in enteroendocrine hormone secretion and metabolic control. Front Endocrinol (Lausanne) 2018;9:576.

8. Chen MC, Wu SV, Reeve JR Jr, Rozengurt E. Bitter stimuli induce $\mathrm{Ca}^{2+}$ signaling and CCK release in enteroendocrine STC-1 cells: role of L-type voltage-sensitive $\mathrm{Ca}^{2+}$ channels. Am J Physiol Cell Physiol 2006;291:C726-C739.

9. Janssen S, Laermans J, Verhulst PJ, Thijs T, Tack J, Depoortere I. Bitter taste receptors and $\alpha$-gustducin regulate the secretion of ghrelin with functional effects on food intake and gastric emptying. Proc Natl Acad Sci USA 2011;108:2094-2099.

10. Kim KS, Egan JM, Jang HJ. Denatonium induces secretion of glucagon-like peptide-1 through activation of bitter taste receptor pathways. Diabetologia 2014;57:2117-2125.

11. Lossow K, Hübner S, Roudnitzky N, et al. Comprehensive analysis of mouse bitter taste receptors reveals different molecular receptive ranges for orthologous receptors in mice and humans. J Biol Chem 2016;291:15358-15377.

12. Andreozzi P, Sarnelli G, Pesce M, et al. The bitter taste receptor agonist quinine reduces calorie intake and increases the postprandial release of cholecystokinin in healthy subjects. J Neurogastroenterol Motil 2015;21:511-519.

13. Iven J, Biesiekierski JR, Zhao D, et al. Intragastric quinine administration decreases hedonic eating in healthy women through peptide-mediated gut-brain signaling mechanisms. Nutr Neurosci Published Online First: 2 April 2018. doi: 10.1080/1028415X.2018.1457841.

14. Deloose E, Janssen P, Corsetti M, et al. Intragastric infusion of denatonium benzoate attenuates interdigestive gastric motility and hunger scores 
in healthy female volunteers. Am J Clin Nutr 2017;105:580-588.

15. Stunkard AJ, Messick S. The three-factor eating questionnaire to measure dietary restraint, disinhibition and hunger. J Psychosom Res 1985;29:71-83.

16. Available from URL: http://www.randomization.com (accessed 16 May 2019).

17. Available from URL: http://www.anzctr.org.au (accessed 16 May 2019).

18. Ryan AT, Luscombe-Marsh ND, Saies AA, et al. Effects of intraduodenal lipid and protein on gut motility and hormone release, glycemia, appetite, and energy intake in lean men. Am J Clin Nutr 2013;98:300-311.

19. Feltrin KL, Little TJ, Meyer JH, et al. Effects of intraduodenal fatty acids on appetite, antropyloroduodenal motility, and plasma CCK and GLP-1 in humans vary with their chain length. Am J Physiol Regul Integr Comp Physiol 2004;287:R524-R533.

20. Steinert RE, Landrock MF, Ullrich SS, et al. Effects of intraduodenal infusion of the branched-chain amino acid leucine on ad libitum eating, gut motor and hormone functions, and glycemia in healthy men. Am J Clin Nutr 2015;102:820-827.

21. Heddle R, Dent J, Toouli J, Read NW. Topography and measurement of pyloric pressure waves and tone in humans. Am J Physiol 1988;255(4 Pt 1):G490-G497.

22. Parker BA, Sturm K, MacIntosh CG, Feinle C, Horowitz M, Chapman IM. Relation between food intake and visual analogue scale ratings of appetite and other sensations in healthy older and young subjects. Eur J Clin Nutr 2004;58:212-218.

23. Nair NS, Brennan IM, Little TJ, et al. Reproducibility of energy intake, gastric emptying, blood glucose, plasma insulin and cholecystokinin responses in healthy young males. Br J Nutr 2009;101:1094-1102.

24. Chalé-Rush A, Burgess JR, Mattes RD. Evidence for human orosensory (taste?) sensitivity to free fatty acids. Chem Senses 2007;32:423-431.

25. Park DC, Yeo JH, Ryu IY, Kim SH, Jung J, Yeo SG. Differences in taste detection thresholds between normal-weight and obese young adults. Acta Otolaryngol 2015;135:478-483.

26. Ryan AT, Feinle-Bisset C, Kallas A, et al. Intraduodenal protein modulates antropyloroduodenal motility, hormone release, glycemia, appetite, and energy intake in lean men. Am J Clin Nutr 2012;96:474-482.

27. Santangelo A, Peracchi M, Conte D, Fraquelli M, Porrini M. Physical state of meal affects gastric emptying, cholecystokinin release and satiety. Br J Nutr 1998;80:521-527.

28. Steinert RE, Luscombe-Marsh ND, Little TJ, et al. Effects of intraduodenal infusion of L-tryptophan on ad libitum eating, antropyloroduodenal motility, glycemia, insulinemia, and gut peptide secretion in healthy men. J Clin Endocrinol Metab 2014;99:3275-3284.

29. Camilleri M, Malagelada JR. Abnormal intestinal motility in diabetics with the gastroparesis syndrome. Eur J Clin Invest 1984;14:420-427.
30. Steensels S, Depoortere I. Chemoreceptors in the Gut. Annu Rev Physiol 2018;80:117-141.

31. Brennan IM, Little TJ, Feltrin KL, et al. Dose-dependent effects of cholecystokinin-8 on antropyloroduodenal motility, gastrointestinal hormones, appetite, and energy intake in healthy men. Am J Physiol Endocrinol Metab 2008;295:E1487-E1494.

32. Fraser R, Fone D, Horowitz M, Dent J. Cholecystokinin octapeptide stimulates phasic and tonic pyloric motility in healthy humans. Gut 1993;34:33-37.

33. Katschinski M, Schirra J, Begliner C, et al. Intestinal phase of human antro-pyloro-duodenal motility: cholinergic and CCK-mediated regulation. Eur J Clin Invest 1996;26:574-583.

34. Schober G, Lange K, Steinert RE, et al. Contributions of upper gut hormones and motility to the energy intake-suppressant effects of intraduodenal nutrients in healthy, lean men - a pooled-data analysis. Physiol Rep 2016;4:e12943.

35. Meyerhof W, Batram C, Kuhn C, et al. The molecular receptive ranges of human TAS2R bitter taste receptors. Chem Senses 2010;35:157-170.

36. Latorre R, Huynh J, Mazzoni M, et al. Expression of the bitter taste receptor, T2R38, in enteroendocrine cells of the colonic mucosa of overweight/obese vs. lean subjects. PLoS One 2016;11:e0147468.

37. Wu SV, Rozengurt N, Yang M, Young SH, Sinnett-Smith J, Rozengurt E. Expression of bitter taste receptors of the T2R family in the gastrointestinal tract and enteroendocrine STC-1 cells. Proc Natl Acad Sci USA 2002;99:2392-2397.

38. Keller KL, Adise S. Variation in the ability to taste bitter thiourea compounds: implications for food acceptance, dietary intake, and obesity risk in children. Annu Rev Nutr 2016;36:157-182.

39. Little TJ, Horowitz M, Feinle-Bisset C. Modulation by high-fat diets of gastrointestinal function and hormones associated with the regulation of energy intake: implications for the pathophysiology of obesity. Am J Clin Nutr 2007;86:531-541.

40. Bell KI, Tepper BJ. Short-term vegetable intake by young children classified by 6-n-propylthoiuracil bitter-taste phenotype. Am J Clin Nutr 2006;84:245-251.

41. Choi SE, Chan J. Relationship of 6-n-propylthiouracil taste intensity and chili pepper use with body mass index, energy intake, and fat intake within an ethnically diverse population. J Acad Nutr Diet 2015;115:389396.

42. Vegezzi G, Anselmi L, Huynh J, et al. Diet-induced regulation of bitter taste receptor subtypes in the mouse gastrointestinal tract. PLoS One 2014;9:e107732.

43. Rolls BJ, Kim-Harris S, Fischman MW, Foltin RW, Moran TH, Stoner SA. Satiety after preloads with different amounts of fat and carbohydrate: implications for obesity. Am J Clin Nutr 1994;60:476-487. 